\title{
Engineering Portfolios at the University of Toronto: DeVeloping Skills for CoMmunication, Professionalism AND LIFE-LONG LEARNING
}

\author{
Chris Ambidge, Alan Chong, Penny Kinnear, Deborah Tihanyi, Lydia Wilkinson \\ Chemical Engineering \& Applied Chemistry [Ambidge]; Engineering Communication Program, University of Toronto \\ chris.ambidge@utoronto.ca, alan.chong@utoronto.ca, penny.kinnear@utoronto.ca, \\ deborah.tihanyi@utoronto.ca, lydia.wilkinson@utoronto.ca
}

\begin{abstract}
In 2005, the University of Toronto's Chemical Engineering and Applied Chemistry Department (CHE), in collaboration with the Engineering Communication Program (ECP), piloted a communications portfolio for second-year students. Over the past seven years the communication portfolio has been expanded into the third-year CHE requirements, adapted for use in the Mechanical and Industrial Engineering Department (MIE) and next year will be used within the Civil Engineering Department. Through a discussion of the CHE and MIE portfolios we compare two different portfolio models and explain how this model has been adapted to its newest context in Civil Engineering at the University of Toronto. Through this approach we aim to show the usefulness of this portfolio model in supporting student development in communication, professionalism and life-long learning, three of the CEAB graduate attributes.
\end{abstract}

Keywords: portfolio, reflection, iteration, graduate attributes, communication

\section{INTRODUCTION}

Portfolios can be used for diverse pedagogical and evaluative purposes. Palmer and Hall provide an excellent overview of how portfolios are currently being used in engineering programs around the world [5]. Some programs use the portfolio as evidence of student attainment of graduate attributes as well as means for students to assess their own understanding of the concepts they are learning [2]. They are also a valuable professional tool when applying for jobs or graduate school positions [5]. Within the University of Toronto's Engineering Faculty portfolios have been adopted as a primary deliverable in teaching and developing engineering communication skills by the Chemical (CHE), Mechanical and Industrial (MIE) and Civil (CIV) Engineering departments. Part of this has been instigated by the Canadian Engineering Accreditation Board (CEAB)'s move to assess programs on the basis of graduate attributes, which include communication skills, professionalism and life-long learning [1]. While there are certain elements and practices common to all three departments, there are also several differences reflected in their cultures and established practices. The differences are presented in Table 1 (next page), which shows the deliverables and their due dates for each of the current portfolios. The CHE Reflections require students to choose an assignment from one of their courses while the Commentaries require students to examine their skills, knowledge and professional goals in the context of the profession of 'chemical engineer'. The integration of the portfolio deliverables with existing course work builds on the strong culture of communication that existed in CHE long before the portfolio courses were established. In MIE, on the other hand, the portfolios were brought in to address the lack of development of communication skills in Mechanical Engineering within the existing curriculum. At the same time, there was a desire to reflect the tangible nature of mechanical engineering - the notion that mechanical engineers produce or improve upon artifacts. To that end, and mindful of the students' workload and a desire to add value to the curriculum, the MIE portfolios focus on helping students present themselves within the profession by linking their experiences - both inside and outside of school - to their potential career paths, culminating in job or graduate school applications. 
Table 1: Portfolios-deliverables, due dates and nature of feedback

\begin{tabular}{|c|c|c|}
\hline & $\begin{array}{c}\text { Deliverables } \\
\text { / due dates }\end{array}$ & Nature of feedback \\
\hline 令 & $\begin{array}{l}\text { Reflection } \\
\text { December } \\
\text { Master resumé } \\
\text { March } \\
\text { Final portfolio } \\
\text { April }\end{array}$ & $\begin{array}{l}\text { Written } \\
\text { Oral } \\
\text { Written }\end{array}$ \\
\hline فิ & $\begin{array}{l}\text { Commentary } 1 \\
\text { October } \\
\text { Commentary } 2 \\
\text { January } \\
\text { Final portfolio } \\
\text { March }\end{array}$ & $\begin{array}{l}\text { Written } \\
\text { Oral } \\
\text { Written }\end{array}$ \\
\hline 令 & $\begin{array}{l}\text { Artifact Analysis } \\
\text { February } \\
\text { Master Resumé } \\
\text { Career Path Analysis } \\
\text { Final Portfolio- } \\
\text { Artifact analysis, } \\
\text { Master Resumé, } \\
\text { Career Path Analysis } \\
\text { April }\end{array}$ & $\begin{array}{l}\text { Oral } \\
\text { Written }\end{array}$ \\
\hline 商 & $\begin{array}{l}\text { Master Resumé } \\
\text { December } \\
\text { Analytical Research } \\
\text { January } \\
\text { Final Portfolio - } \\
\text { Cover letter, Resumé } \\
\text { and revisions } \\
\text { April }\end{array}$ & $\begin{array}{l}\text { Written } \\
\text { Written } \\
\text { Written }\end{array}$ \\
\hline
\end{tabular}

Tables 2, 3 and 4 below, indicate the relevant CEAB Graduate Attribute and the portfolio deliverable(s) that address that attribute.

Outcomes for communication skills (Table 2) focus on the ability to credibly communicate engineering knowledge and use the multiple modes of communication common to engineering practice. As well, the notion of iteration is significant in developing these skills, partly for the role it plays in learning and partly for the parallel with engineering work, which relies on iterative design for successful outcomes. In terms of professionalism (Table 3, next page), there are two key outcomes: the first uses both simulated and real engineering situations in which students practice being engineers and the second, building on the first, the opportunity to reflect on these practices. The life-long learning outcome (Table 4, next page), builds on the reflection and iteration in the portfolios and the larger curriculum; given multiple opportunities to approach and practice within novel engineering situations, students develop the strategies required to deal with the continually evolving needs of the profession.
Table 2: Communication Skills: outcomes in portfolio assignments

\begin{tabular}{|c|c|c|c|}
\hline & $\begin{array}{l}\text { Identify \& } \\
\text { credibly } \\
\text { communicate } \\
\text { engineering } \\
\text { knowledge }\end{array}$ & $\begin{array}{l}\text { Use different } \\
\text { modes of } \\
\text { communication }\end{array}$ & $\begin{array}{l}\text { Develop } \\
\text { communication } \\
\text { through an } \\
\text { iterative } \\
\text { process }\end{array}$ \\
\hline 气ิ & $\begin{array}{l}\text {-Reflections } \\
\text {-Master } \\
\text { Resumé } \\
\text {-Portfolio } \\
\text { Summary } \\
\text {-Web Page* } \\
\text { CHE204/213 } \\
\text {-Consulting } \\
\text { Project* } \\
\text { CHE230 }\end{array}$ & $\begin{array}{l}\text { - Reflections } \\
\text {-Master } \\
\text { Resumé } \\
\text {-Portfolio } \\
\text { Summary } \\
\text {-Web Page* } \\
\text { CHE204/213 } \\
\text {-Consulting } \\
\text { Project* } \\
\text { CHE230 }\end{array}$ & $\begin{array}{l}\text { - Reflections } \\
\text {-Annotated } \\
\text { Revision } \\
\text { - Master Resume } \\
\text { - Portfolio } \\
\text { Summary } \\
\text {-Web Page* } \\
\text { CHE204/213 } \\
\text {-Consulting } \\
\text { Project* } \\
\text { CHE230 }\end{array}$ \\
\hline 今ે & $\begin{array}{l}\text { - Commentaries } \\
\text {-Portfolio } \\
\text { Postscript } \\
\text { - Lab Report } \\
\text { Presentations* } \\
\text { CHE326 }\end{array}$ & $\begin{array}{l}\cdot \text { Commentarie } \\
\text { s } \\
\text {-Portfolio } \\
\text { Postscript }\end{array}$ & $\begin{array}{l}\text { - Commentaries } \\
\text { - Lab Report } \\
\text { Presentations* } \\
\text { CHE326 }\end{array}$ \\
\hline 令 & $\begin{array}{l}\text {-Artifact } \\
\text { Analysis } \\
\text {-Master } \\
\text { Resume } \\
\text {-Career Path } \\
\text { Analysis }\end{array}$ & $\begin{array}{l}\text { - Career Path } \\
\text { Analysis }\end{array}$ & $\begin{array}{l}\text {-Artifact } \\
\text { Analysis }\end{array}$ \\
\hline 气̂̀ & $\begin{array}{l}\text {-Master } \\
\text { Resume } \\
\text {-Analytical } \\
\text { Research }\end{array}$ & & $\begin{array}{l}\text { - Master Resume } \\
\text {-Analytical } \\
\text { Research }\end{array}$ \\
\hline
\end{tabular}

In general terms the pedagogy of portfolios rests on the practice of reflection. Reflection, or in Vygotskyian terms, consciousness, is critical to an individual's ability to learn and develop higher mental functions, including principled problem-solving or the development of abstract concepts [6]. The CHE297 portfolios provide opportunities for students to identify strengths and weaknesses in various course content areas, as documented in the course deliverables. Here they have the opportunity to develop not just communication concepts but also fundamental chemical engineering concepts. The CHE397 and MIE297 and MIE397 portfolio assignments provide the mediational means students may use to develop their understanding of their own engineering knowledge, skills, goals and experiences. 
Table 3: Professionalism: outcomes in portfolio assignments

\begin{tabular}{|c|c|c|}
\hline & $\begin{array}{l}\text { Display professional } \\
\text { etiquette and conduct } \\
\text { with clients, } \\
\text { colleagues and } \\
\text { society at large }\end{array}$ & $\begin{array}{l}\text { Reflect on and analyze } \\
\text { place in the engineering } \\
\text { profession }\end{array}$ \\
\hline 气ิ & $\begin{array}{l}\text { - Master Resumé } \\
\text {-Web Page* } \\
\text { CHE204/213 } \\
\text {-Consulting Project* } \\
\text { CHE230 }\end{array}$ & $\begin{array}{l}\text {-Master Resumé } \\
\text { Summary } \\
\text { •Portfolio Summary }\end{array}$ \\
\hline$\hat{\overbrace{}}$ & $\begin{array}{l}\cdot \text { Commentaries } \\
\cdot \text { Lab Report } \\
\text { Presentations* } \\
\text { CHE326 }\end{array}$ & $\begin{array}{l}\text { - Commentaries } \\
\text {-Portfolio Postscript }\end{array}$ \\
\hline 令 & -Master Resumé & - Career Path Analysis \\
\hline$\hat{\hat{\jmath}}$ & $\begin{array}{l}\text {-Cover } \\
\text { letter/Statement of } \\
\text { Purpose }\end{array}$ & $\begin{array}{l}\text {-Analytical Research } \\
\text { - Cover letter/Statement of } \\
\text { Purpose }\end{array}$ \\
\hline
\end{tabular}

Table 4: Life-long learning: outcomes in portfolio assignments

\begin{tabular}{|c|c|}
\hline & $\begin{array}{l}\text { Move beyond protocols/formulae/templates to } \\
\text { analyze novel situations and address them } \\
\text { appropriately }\end{array}$ \\
\hline کิ & $\begin{array}{l}\text { - Annotated Revision } \\
\text {-Portfolio Summary } \\
\text { - Web Page* CHE204/213 } \\
\text {-Consulting Project* CHE230 }\end{array}$ \\
\hline$\hat{\mathrm{e}}$ & $\begin{array}{l}\text { - Commentaries } \\
\text {-Portfolio Postscript }\end{array}$ \\
\hline 气ิ & -Career Path(s) Analysis \\
\hline$\hat{\check{c}}$ & $\begin{array}{l}\text { - Cover Letter/Statement of Purpose } \\
\text {-Job-specific Resumé }\end{array}$ \\
\hline
\end{tabular}

Reflection also has a central role in the development of engineering identities as Eliot and Turns [3] have shown.
The reflection in the case of the portfolios is mediated by both the process of choosing the components of the portfolio and the interactions with instructors. Both the portfolio assignments themselves and the interactions with instructors require a close examination and analysis of the efficacy of language and rhetorical strategies used in engineering documents produced for specific audiences and purposes. It also refers to the examination and analysis of a student's own knowledge, skills and values within an engineering context that can contribute to a student positioning her/himself within the engineering profession and the development of a professional identity and practice.

The article will begin with a detailed portrait of the content, pedagogy and assessment of the Chemical Engineering Portfolio as it has served as a model for subsequent portfolio course development. Next we will consider the ideal goals and challenges of a portfolio within an engineering program from both student and institutional perspectives. The article will conclude with a report of how Civil Engineering is adapting the portfolio for the 2012-13 academic year.

\subsection{Chemical Engineering Portfolio as Prototype}

Originally conceived as a method to ensure that all CHE students had effective communication skills upon graduation, and simultaneously to remediate those students with more significant communication challenges, the CHE portfolio courses use a number of different strategies to respond to the individual communication needs of each student. Utilizing the final portfolio as a way of measuring student communication skills, the portfolio courses offer one-on-one meetings with a Communication Instructor, or CI, as well as coaching and alternative programming for students who have been identified as requiring remediation.

The CHE297 final portfolio originally consisted of three to five items of communication or artifacts, corresponding reflections and a Portfolio Summary. Students selected the artifacts from their course deliverables in other engineering courses; these functioned as evidence for the reflections, which identified the strengths of each item, its weaknesses, and future strategies for improvement. The artifacts were selected to cover a number of categories: oral, written, individual, team, research-based and iterative. The Portfolio Summary synthesized material from across the various reflections to identify common patterns and provide new insights.

This year the number of required Reflections decreased from three to two, in order to accommodate new deliverables that have been added to the portfolio. The annotated revision asks students to apply the strategies for improvement identified in one of their reflections to the artifact that they are discussing. Rather than revising it 
completely, they annotate the artifact to sketch out the changes they would make if they were to complete the activity again. This new portfolio component was developed in response to a perceived disconnect between the improvement strategies that students typically identified and their artifacts.

To provide students with professionalization sooner, a need that many students voiced (and that also appears in the CEAB graduate attributes) a master resumé component was also added. This document asks students to bring together all of their relevant professional and personal experience into a master resumé or curriculum vitae, that is organized into easily searchable categories to enable retrieval of items for their future job specific resumés.

The master resumé anticipates the focus of the third year portfolio, which moves beyond the student as an individual and their particular communication skillset, to consider their place in the Engineering profession. In this portfolio, students write 3-5 commentaries on various skill areas from the following list: using research and applying theory in engineering; using rhetorical strategies effectively in different genres of written communication; using oral communication effectively in different contexts; ethical implications of engineering choices; communicating technical information to the larger society; communicating with peers/effective group dynamics in the development of research and design; communication around cultural differences; the role of teaching/mentoring in engineering practice; and the role of leadership in engineering practice. Within these commentaries students are expected to define the skill area and bring together multiple examples to support their discussion of this skill area. This evidence may be drawn from their own experiences, or from research sources such as case studies.

CHE397 students are asked to produce a Portfolio Postscript as their summative document. This element of the portfolio is assessed on the student's ability to demonstrate a clear understanding of the depth and breadth of engineering practice, while developing a coherent argument and exhibiting their critical thinking skills. Students are encouraged to be creative here, and the Postscript has taken many forms, including blogs, hypothetical interviews with a future self, music analysis and performance, short fiction, origami, and, most recently, an explosion box in which the student's personal and professional growth was symbolized through the multiple layers.

Originally, the grading of portfolios was assigned arbitrarily between sessional instructors hired for small contracts in the course. In order to promote consistency in grading and to provide extra support for a course with no designated in-class instructional time, we have shifted to a model in which each student is assigned a Communication Instructor (CI). Students are encouraged to utilize their $\mathrm{CI}$ as their first point of contact for the course, and are responsible for booking appointments to discuss and receive feedback on their course deliverables. In this way students are provided with ongoing support in communication and more consistent grading. The regular CI feedback allows students to improve between iterations of the portfolio items; and the regular contact with students helps CIs develop teaching strategies that are specific to the needs of each student. This year, CHE297 students met with their CI for a one-on-one explanation of their performance on Reflection 1; they met twice to discuss their content and organization of the CHE204/213 webpage assignment, an item for an affiliated course that incorporates significant communication content; they also met with their CI for a practice interview that complemented their completion of the master resumé. CHE397 students met with their CIs for feedback on Commentary 1. In April, the CIs grade new items that have been added to the portfolio, and, along with material from the year, provide their students with a final grade on the portfolio.

Rather than using a number or letter scale, portfolios receive one of five colour classifications: blue, green, yellow, red or salmon. At the registrar's office, these grade levels coincide with a credit (CR) or in progress (IPR). Blue and green portfolios both receive credit in the course. Blue portfolios are exceptionally strong and also earn the student a letter of commendation (the Chair's Award for Excellence in Communication). Yellow portfolios require some revision, which can be undertaken independently. These students can look to their written feedback for revision strategies, and are also supported through a number of help sessions in the fall. Red portfolios have more substantial issues, and these students work closely with their CI through a minimum of four one-on-one sessions during the fall semester to revise the contents. The yellow and red portfolios receive an IPR in the course until an acceptable version is submitted. CHE297 students can enroll in CHE397 while they are revising their portfolio. Ideally, the lessons that they take away from the help sessions and meetings can be effectively applied to their next portfolio.

The salmon classification was added more recently in response to a growing number of students who produced portfolios in which poor mechanical English skills obscured meaning. These students, typically comprising $10-13 \%$ of the student body, must complete the Academic Reading and Writing through Email (ARWE) program over the summer. ARWE asks students to write email responses to a variety of articles. The response format provides them with an opportunity to consistently practice their writing skills, while biweekly meetings with a Communication Instructor focus on correcting mechanical errors that appear in their written work. 


\subsection{The Mechanical Engineering Portfolio}

The MIE portfolio, in its second year, reflects a very different perspective. Unlike the CHE portfolios, which use course work as the main source/prompt for student reflections, the MIE portfolios do not focus primarily on course assignments for their activities. Instead, students mine their experiences - both inside and outside of school-in helping them to identify their knowledge, skills and values towards identifying potential career paths. As it now stands, MIE 297 requires students to produce a $\mathrm{CV}$ that serves as a data base from which they can assemble position specific resumés; a set of 'artifact analyses' that require students to describe and mine their coursework, employment, volunteer, etc. experiences for knowledge, skills, personal characteristics; and a career path analysis that requires students to identify one or more possible career paths and use information from their CVs, artifact analyses and job or graduate school specific research they have done to justify that particular career path. This work leads to MIE 397, which focuses on putting together either a job specific application (cover letter, resumé, application) or graduate school application (statement of purpose, resumé). The focus is pragmaticgetting a job or getting a graduate school slot. Reflection still has a role (in the MIE297 course, stepping back and trying to see how knowledge, skills, passions, and values interact to guide an individual) but reflection is not focused on student strengths and weaknesses as identified in specific assignments or on the profession and how a student may fit in.

The MIE portfolios also emphasize the central role of the CI; however, a major difference here is the use of engineering graduate students (as opposed to instructors from the Engineering Communication Program, ECP) in the CI role. As with the CHE portfolios, students are assigned a CI at the beginning of the course, and this person gives feedback (both written and verbal) and evaluates all work for the portfolio. However, the use of engineers allows for an added layer to the CI role; here, CIs use their personal experience as engineering students and engineers to become role models and mentors for students - in addition to providing communication instruction and feedback.

MIE students must receive credit for MIE 297 before they can enroll in MIE 397. They cannot take the courses concurrently. Students will have the summer to revise their portfolios if they have not met the requirements. They will be asked to do so either independently, using the CI's feedback, with limited face-to-face contact and feedback from their $\mathrm{CI}$ or if language error/usage compromises meaning they may be assigned a language coach and/or asked to participate in the ARWE program over the summer.

\section{THE PORTFOLIOS: ESSENTIAL ACTIVITIES AND PEDAGOGY}

While providing students with a space to develop key communication skills, the portfolio courses must often adapt to significant challenges at the individual, or student, and institutional levels. In this section, we discuss the ideal framework for effectively delivering the portfolios alongside the actual challenges to this delivery at both these levels.

\subsection{Student - Ideal}

The portfolio as it is conceptualized at UofT provides a site where students can develop a professional identity and professional communication skills. This is accomplished through the integration of instruction in principles of communication, rhetorical strategies, language use and the use of iteration in the production of both engineering documents and reflections.

To accomplish these goals a student engages in an iterative reflection, composition and revision process to produce the portfolio elements, either as part of an engineering course or as a portfolio course. Ideally this is done through a combination of direct instruction in either a communication or engineering class setting and individual tutorial sessions with a Communication Instructor. In an engineering class context students are introduced to the principles of professional communication and rhetoric, specific to the course assignment. In the portfolio course, which focuses on the assembly/development of a portfolio more work is done through reflection in order to facilitate an awareness of the individual students' knowledge, skills and personal qualities and how those are communicated within a professional engineering context.

Working with a single CI over the duration of a course, either integrated with an engineering content course or in a portfolio course, facilitates the establishment of a teaching/learning relationship. This dedicated relationship also contributes to more consistent feedback and evaluation for the student. The CI can begin to observe patterns that help to distinguish between language use issues, rhetorical issues and engagement issues. Such knowledge allows the CI to provide specific, contingent support to help a student develop control over both the professional rhetoric and language used to produce technical reports, proposals, client communication and presentations. For example, the instructor can determine a hierarchy of needs and address them with the student over time and thus support student self-regulation. CIs may target argument, making claims and providing relevant evidence, in a design document or a proposal. Later on, the CI may challenge the student to recognize different levels of formality in the language used in a document 
before asking the student to revise and use a more professional register. The CI will also be able to recognize when the issue may be second language development and offer a variety of supports as well as strategies to address the language learning and usage needs. Note that with the use of engineering CIs (as with the MIE297 and MIE397 portfolios), students get an added element of guidance beyond communication to professional/career development.

Considering the role of affect in cognitive development, the teaching/learning relationship a CI may be able to foster with students can provide the context where both CI and student may comfortably challenge assumptions about engineering communication and the role of a portfolio. The CI may also be able to challenge students over their engagement or non-engagement with portfolio activities.

\subsection{Student - Challenges}

While the individual relationship fostered through regular meetings and discussion should provide a platform for sustained student engagement, it is often compromised by the practical challenges of scheduling and enforcing these meetings. These challenges arise on the one hand from the very real constraints of an undergraduate student's schedule, and on the other from the perceived importance of portfolio courses within the required curriculum. As we will discuss in greater detail under Institutional Challenges, students often perceive the portfolio course as secondary to their other graduation requirements. Its status as a credit or non-credit requirement that is inconsistently applied across the faculty can make it difficult to justify the extended time commitment required by students for its successful completion.

Despite efforts to have students contact their Communication Instructor early and coordinate meeting times throughout the semester, these meetings are often scheduled on an ad-hoc basis, when students are reacting to impending deadlines for course deliverables. Practically, it is often difficult to schedule last minute meetings around busy student and CI schedules, and occasionally students are given the option of meeting with an alternate CI or receiving feedback via email; both options fail to deliver the personalized instruction offered by recurring one-on-one meetings.

Although students benefit from observing internal deadlines and receiving formative feedback for each portfolio item throughout the semester, there is no punitive consequence for students who ignore these deadlines. Sometimes students attempt to discuss multiple deliverables in a single CI meeting late in the year. This type of one-off meeting makes it difficult to provide students with customized feedback based on extended contact. The need to cover multiple deliverables in a single session often means that no item receives thorough discussion. Occasionally, students do not utilize CI support at all.

In an ideal scenario every student would recognize the value of a sustained relationship with a Communication Instructor, who could continue to work with them beyond their second and third years to provide them with feedback in their capstone course and on professional documents in their final year. Unfortunately some students only realize the value of fostering this relationship after completing the second year portfolio. Not surprisingly many students seem more receptive when they have entered their third year, have been exposed to multiple engineering documents, and have developed an understanding of the value of effective communication in their discipline.

\subsection{Institutional - Ideal}

Given that the portfolios function as a site where students can work towards a professional identity, the success of the program lies to a large extent on collaboration - and buy-in-from engineering faculty. In teaching communication, ECP faculty are often at a disadvantage because of the fact that we are not engineers; such a disadvantage grows if we alone presume to instruct students on the elements of professional practice. In contrast, engineering faculty-many of whom come to teaching via industry - can speak with authority on "being an engineer." Moreover, engineering faculty, by virtue of their experience, can provide persuasive evidence (living proof) of why certain types of communication and reflection are necessary to the students' training.

Through links to work in core courses in the curriculum, as well as consultation in the development of portfolio deliverables, departmental and faculty involvement increases the effectiveness of teaching and learning, as well as the investment of the students themselves. In CHE, a close collaboration with the CHE230 Environmental Chemistry course involves, on the one hand, ECP collaboration on communication resources, rubrics and feedback on course deliverables and, on the other, integrated reflection assignments (which mirror the portfolio reflections). With an iterative consulting assignment, students in CHE230 use the reflection central to the portfolios to improve their disciplinary communication. Similarly, consultation with both CHE and MIE engineering faculty lead to the implementation of a curriculum vitae component in each department's portfolios, underscoring not only another form of disciplinary communication but also allowing students to move beyond the classroom to identify formative educational experiences. Students see immediate benefits - in the former case, in terms of 
grades in a course, in the latter, more effective ways to present themselves to potential employers.

Of course, another key element to institutional commitment is the mandatory nature of the portfolio courses. While they do not factor into a student's grade point average, they are mandatory requirements for graduation. This compulsion provides necessary buy-in from the students. At the other end of the spectrum, rewards are provided for particularly meritorious students, in CHE in the form of "Chair's Awards for Excellence in Communication"; in MIE, this past year, in the form of certificates recognizing the top deliverables in the portfolio.

\subsection{Institutional - Challenges}

While we have been fortunate in the level of departmental and faculty buy-in for the portfolios, we are nonetheless faced with the constraints of the educational setting, the most pressing of which is time. Developing meaningful and effective links between the portfolios and core courses involves collaboration before, during and after the courses take place; when time is at a premium, this type of collaboration can be difficult to sustain. As a result, there is a risk of only superficial links to assignments, without adequate disciplinary input on the one side and/or communication instruction on the other.

Of course, we are also subject to budgetary constraints within the academic setting. The cost of portfolio courses - along with their satellite involvements in the rest of the curriculum - can vary widely. Perceptions of what is essential to student development can vary between engineering and ECP faculty, and, times being what they are, often the more labour-intensive (and hence more economically costly) initiatives are the first to be sacrificed. In our experience, for example, the effectiveness of ARWE (Academic Reading and Writing through E-mail) for the roughly $10 \%$ of students who require additional language support has been proven in practice; however, due to the amount of time required on the part of instructors to deliver the program, departments can be reluctant to pay for them.

The mandatory nature of the portfolio can also prove problematic. Students - and faculty-often see the portfolio as an "extra" course requirement on top of the regular workload (a requirement that, at this stage, is not mandatory for all departments in engineering). At best, this additional work can be resented by students; at worst, holding students to account for meeting the requirements of this "extra" course-i.e., not allowing them to graduate-is difficult to enforce.

\section{ADAPTING THE PORTFOLIO MODEL TO OTHER CONTEXTS}

The successes and challenges faced by these iterations of the portfolio model can be used to inform and shape how we use the portfolios in meeting specific learning objectives as well as graduate attributes. One example of this adaptation comes from the Civil Engineering (CIV) Department at the University of Toronto, where these models are currently being revised for use in mounting a third year portfolio course that will differ significantly from the ones mentioned above. These adaptations emerge from disciplinary differences, but also from departmental ones, and demonstrate the flexibility of the portfolio model as a tool for teaching communication.

One essential disciplinary difference between CIV and other disciplines involves the importance and nature of visual communication. CIV students, in fact, are required to take a second-year technical drawing course in which they learn disciplinary practices around technical drawings, focusing on structures. These techniques and best practices are then reinforced in upper year projects, in which students must demonstrate their ability to produce visuals that meet disciplinary conventions. The importance of this visual communication calls for an explicit visual component as part of the portfolio, implemented as a constraint on their selection process: at least one entry in the portfolio must be primarily visual, and another must provide an example of how textual and visual communication interoperate in explaining a design. Placing disciplinary specific constraints on the selection process can help ensure that, for any discipline, the portfolio can appropriately reflect the skills required in the discipline. For another example, Engineering Physics students might be required to submit a complex lab procedure of their own design; or, Mineral Engineering students might be asked to provide recommendations from an Environmental Assessment. Though these examples do not enforce a different mode of communication, they do allow the portfolio composition to speak to skills important to the discipline.

The challenges of student workload mentioned above have been a primary concern in the development of the CIV portfolio, especially given the particularly heavy requirements of their third year. One simple strategy for mitigating this workload issue would have been to move the portfolio to their senior year; however, this move would not provide students with sufficient time to develop their communication skills or to revise their portfolios to passing levels. The approach to be taken in CIV will instead be to provide support before and during the writing process. Students will meet with instructors near the beginning of the year to select assignments from their other courses appropriate for the portfolio, and throughout the year as they write the documents: this will allow for a conversation on communication throughout the year 
which will both aid in their portfolio development as well as in their other coursework. In this case, workload concerns are addressed through minor changes in timing and nature of the portfolio consultations, though other possibilities for workload management still exist.

Finally, as also indicated above, student buy-in remains an important consideration: initial consultations with students in Civil Engineering have indicated a strong desire for professional skills and industry voices in their portfolio development. These concerns have been addressed in other departments by specifying that a resumé be part of the portfolio, and we could potentially strengthen the professionalism components by requiring part of the portfolio to be outward facing, presented as part of an application package. This is particularly appropriate for CIV students, whose design work in their undergraduate years is an important part of their appeal to employers. Furthermore, the portfolio presents an important opportunity to create industry-university ties so desired by the students through communication focused activities, such as those created through Duke University's Alumni Reader project [4]. In that initiative, alumni volunteers provide formative feedback on student assignments throughout the year in a variety of courses. In the CIV Portfolio course, we envision - in a small scale pilot project to start - alumni or volunteers from industry partners meeting with students throughout the year, bringing to bear their experience in the workplace to help students in the process of writing, selecting, and positioning items for their professional portfolios.

\section{CONCLUSION}

The challenges to mounting a successful portfolio course identified above will likely exist in many situations, and other challenges are likely to present themselves, depending on the discipline and nature of the institution. However, those same situational parameters will likely present their own, unique possibilities for addressing those challenges, as demonstrated in the development of the portfolio courses across departments at the University of Toronto. These evolutions demonstrate the flexibility of a portfolio model for teaching communication, professionalism, promoting lifelong learning, and ultimately, as a site for both the development and measurement of graduate attributes.

\section{References}

[1] Canadian Engineering Accreditation Board: Accreditation Criteria and Procedures. Ottawa, Ontario: Engineers Canada, 2010, 83 pp. \{ISSN-1708-8054\} Available as of April 20, 2012 from http://www.engineerscanada.ca/e/files/Accreditation_Criteri a_Procedures_2010.pdf

[2] James H. Hanson and Julia M. Williams, "Using writing assignments to improve self-assessment and communication skills in an Engineering Statics course," Journal of Engineering Education, vol. 97, no 4, pp. 515-529, 2005.

[3] Matt Eliot and Jennifer Turns, "Construction professional portfolios: Sense-making and professional identity development for engineering undergraduates," Journal of Engineering Education, vol. 100, no 4, pp. 630-654, 2011.

[4] Cary Moskovitz. "The Duke Reader Project: Engaging the University Community in Undergraduate Writing." Liberal Education, vol. 97, no. 3-4, pp. 48-51. April 13 ${ }^{\text {th }}, 2012$.

[5] Stuart Palmer and Wayne Hall, "Online student portfolios for demonstration of engineering graduate attributes," in Proc. ASCILITE Australasian Society for Computers in Learning in Tertiary Education Conf., ASCILITE 2006, Lina Markauskaite, Peter Goodyear and Peter Reimann, (eds.) (Sydney, Australia; 3-6 December 2006), 10 pp., 2006.

[6] L. S. Vygotsky, Lectures on psychology: The collected works of L. S. Vygotsky, Volume 1. Problems of general psychology. New York, Springer, 1988, 412 pp. \{ISBN 030642441X\} 